\title{
ADAPTIVE PROPORTIONAL-INTEGRAL FUZZY LOGIC CONTROLLER OF ELECTRIC MOTOR DRIVE
}

\author{
Chiheb Ben Regaya* - Fethi Farhani - Abderrahmen Zaafouri - Abdelkader Chaari
}

University of Tunisia, Engineering Laboratory of Industrial Systems and Renewable Energies (LISIER) 5 Av. Taha Hussein, BP 56, 1008 Tunis, Tunisia

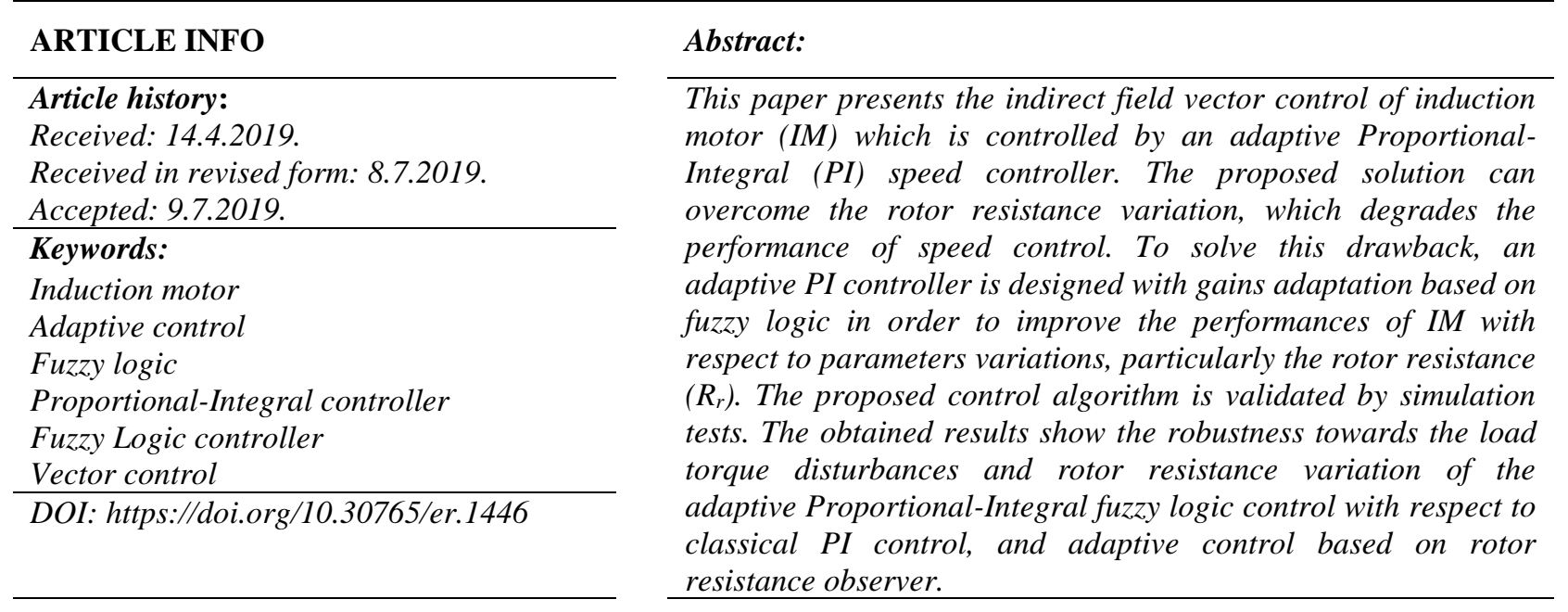

\section{Introduction}

The first control applications of asynchronous machines were limited only at steady state. These applications were based on the scalar command, also known as the (V/f) control [1]. This technique is characterized by its simplicity and relatively small cost of implementation. Nevertheless, it cannot guarantee a high performance, in fact due to the existence of an intrinsic coupling between the torque and flux. To overcome the drawbacks of the scalar control, additional sophisticated control techniques have been developed, namely, the direct torque control (DTC: Direct Torque Control) and flux oriented vector control (FOC Field Oriented Control) [2]-[5]. In the literature, there are different vector control strategies that differ essentially by the choice of the $(\mathrm{d} ; \mathrm{q})$ axes orientation.

The most common is the rotor flux oriented vector control. Recently, several studies have been devoted to development of non-linear control techniques for induction motor. These techniques include: control based on the technique of input-output linearization [6], sliding mode control [7], [8], backstepping control [9]-[13]. The major drawback of these control techniques is their sensitivity to parametric variations, in particularly, the rotor resistance $\left(R_{r}\right)$ which can change with the temperature [14]. Indeed, if the rotor resistance value undergoes a variation, it will affect directly the open loop slip estimator and deteriorates the controller's performances [6], [15].

To solve this problem, many researches have been focused toward the adaptive control in order to ameliorate the control performance, vis-a-vis the parametric variations with the use of different type of observers. Among them, the adaptive control of IM using a Model Reference Adaptive Systems (MRAS) observer, but in [14], [16], the authors claim that this method doesn't guarantee a good speed tracking. The works presented in [17] which is based on sliding mode observer, that the obtained results make the chattering phenomenon appear, which affect negatively the performance control of the IM. The works presented by [15], [18]-[20], which concerns the Backstepping and the Luenberger observers respectively, show that the major drawback of this type of adaptive control is the instability of the induction motor at low speed, when the difference between real and estimated rotor resistance exceeds $10 \%$.

\footnotetext{
${ }^{*}$ Corresponding author

E-mail address: chiheb.benregaya@issatgf.rnu.tn
} 
During the last decade, the number of fuzzy logic applications have increased significantly, especially for uncertain nonlinear systems [4], [5], [21]-[25].

The work presented in [5], shows that new fuzzy logic direct torque control scheme guarantees many improvements such as minimizing the rise time, torque and flux ripples. Moreover, the authors in [26] present a new design for the PI-fuzzy controller which illustrates the potential of the Iterative Feedback Tuning (IFT) employed in connection with fuzzy control in the complex plants.

To solve optimization problems for the Takagi-Sugeno fuzzy controller, the authors in [27] propose a new design of this type of controller using swarm intelligence optimization algorithms. Recently, the type- 2 fuzzy logic systems have been applied to design a novel reliable static output-feedback controller for discrete-time interval systems with mixed $\mathrm{H}_{2} / \mathrm{H}_{\infty}$ performance.

The main purpose of this paper is to design an adaptive control scheme for induction motor that allow high performance using the fuzzy logic.

The idea is to design an adaptive PI speed controller which can ensure a good speed tracking in case of rotor resistance variation. The PI gains adaptive mechanism is ensured using a fuzzy logic controller for each gain $\left(k_{p}\right.$ and $\left.k_{i}\right)$. The proposed control law does not suggest the use of any observer mentioned above, so it does not increase the control scheme complexity, and guarantee a good rotor flux orientation when the rotor resistance undergoes a variation.

This paper starts with a presentation of the mathematical model of the induction motor, and we briefly review the indirect vector control strategy. The description of the proposed algorithm used to handle the induction motor rotor resistance effect based on fuzzy logic is developed in the third section. Section 4 is devoted to the simulation results, and a comparative study with classical PI control and other recent works is made with some robustness tests. Finally, the conclusion and comments are given in Section 5.

\section{IM modeling and vector control strategy}

Vector control of induction motor is based on Park transformation involving the stator and rotor electrical frequencies $\omega_{s}$ and $\omega_{r}$ respectively. In a synchronous rotating reference frame, the mathematical dq model of the IM is given by the following equations [7]:

$$
\left\{\begin{array}{l}
\frac{d}{d t} i_{s d}=-\lambda i_{s d}+\omega_{s} i_{s q}+k \beta_{r} \phi_{r d}+k \omega_{r} \phi_{r q}+\mu V_{s d} \\
\frac{d}{d t} i_{s q}=-\omega_{s} i_{s d}-\lambda i_{s q}-k \omega_{r} \phi_{r d}+k \beta_{r} \phi_{r q}+\mu V_{s q} \\
\frac{d}{d t} \phi_{r d}=M \beta_{r} i_{s d}-\beta_{r} \phi_{r d}+\omega_{s l} \phi_{r q} \\
\frac{d}{d t} \phi_{r q}=M \beta_{r} i_{s q}-\omega_{s l} \phi_{r d}-\beta_{r} \phi_{r q}
\end{array}\right.
$$

where:

$V_{s d}, V_{s q}: d$ and $q$ stator voltages components;

$i_{s d}, i_{s q}: d$ and $q$ stator currents components;

$\phi_{r d}, \phi_{r q}: d$ and $q$ rotor flux components;

$L_{s}, L_{r}:$ stator and rotor inductances;

$R_{s}, R_{r}$ : stator and rotor resistances;

$M, \sigma:$ mutual inductance and total linkage coefficient;

$\omega_{r}, \omega_{s}:$ rotor and stator frame angular velocity;

$\omega_{s l}=\omega_{s}-\omega_{r}:$ slip angular frequency. 
and the constants are defined as follows:

$$
\lambda=\mu R_{s r}, \mu=\frac{1}{\sigma L_{s}}, R_{s r}=R_{s}+\frac{M^{2}}{L_{r}^{2}} R_{r}, \sigma=1-\frac{M^{2}}{L_{s} L_{r}} .
$$

The difficulty of controlling an induction motor resides in the fact that there is a complex coupling between the input, output and internal machine variables such as torque, flux and speed or position. In 1971, Blaschke proposed a new control theory, which called for the oriented flux vector control that can bring the induction motor to the current DC machine with separate excitation [3]. This control theory imposes that $\phi_{r d}=\phi_{r}$ and $\phi_{r q}=0$, to control separately the torque and flux by the stator currents $\left(i_{s q}\right)$ and $\left(i_{s d}\right)$ respectively.

The Field Oriented Control (FOC) strategy can then ensure the decoupling between torque and flux dynamics, but the performances of the FOC are related to the actual motor parameters. Indeed, the motor parameters can vary with the inverter frequency, the temperature and the current amplitude variations. The most critical changing parameter is the rotor resistance $\left(R_{r}\right)$ [15], [16], [28]. In fact, the nonlinear mathematical model presented in the equation (1) can be rewritten as follows:

$$
\left\{\begin{array}{l}
\frac{d}{d t} i_{s d}=-\lambda i_{s d}+\omega_{s} i_{s q}+k \beta_{r} \phi_{r}+\mu V_{s d} \\
\frac{d}{d t} i_{s q}=-\omega_{s} i_{s d}-\lambda i_{s q}-k \omega_{r} \phi_{r}+\mu V_{s q} \\
\frac{d}{d t} \phi_{r}=M \beta_{r} i_{s d}-\beta_{r} \phi_{r} \\
\frac{d}{d t} \phi_{r q}=M \beta_{r} i_{s q}-\omega_{s l} \phi_{r}=0 \\
J \frac{d}{d t} \omega_{r}=\left(C_{e}-C_{r}\right)-\frac{f}{J} \omega
\end{array}\right.
$$

The slip frequency and the electromagnetic torque are given by the following equations:

$$
\begin{gathered}
\omega_{s l}=\frac{R_{r} M}{L_{r} \phi_{r}} i_{s q} \\
C_{e}=\frac{3}{2} \frac{n_{p} M}{L_{r}}\left(\phi_{r d} . i_{s q}\right)
\end{gathered}
$$

The equation (2) shows the non-linearity of the induction motor which can be solved by adding the compensations terms as illustrated in Figure 1. 


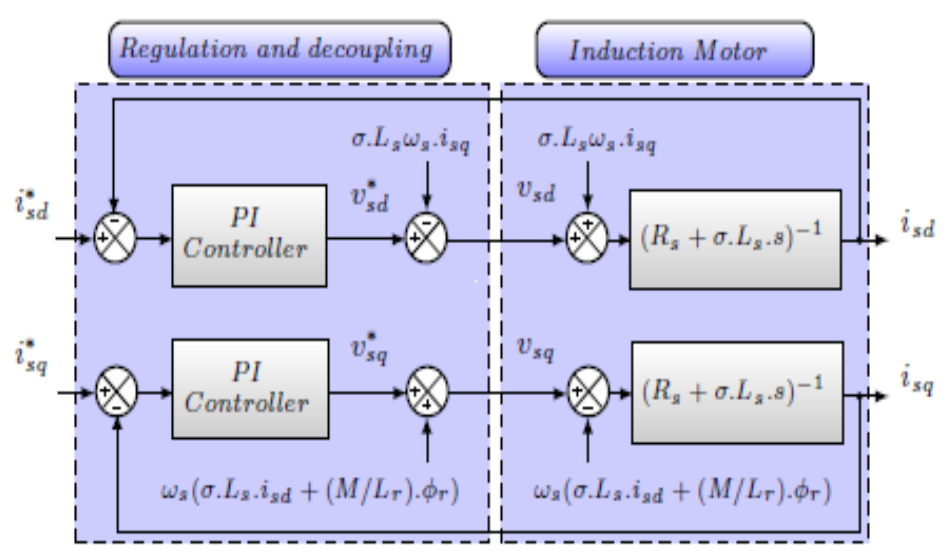

Figure 1. Block scheme of conventional PI current controller with compensation terms.

The PI speed controller determines the reference torque to maintain the same speed. So, to calculate the controller parameters, it must be assumed that the dynamics of the stator currents is not involved in the dynamics of the speed control loop, because the mechanical constant time is considerably greater than the electric constant time. The PI speed control loop is given by Figure 2:

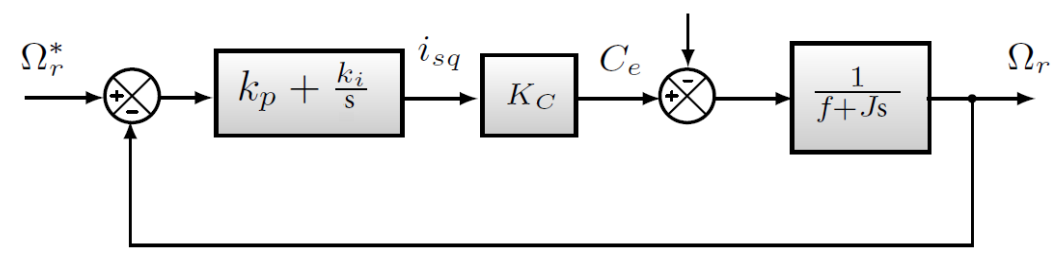

Figure 2. Block scheme of the PI speed control loop.

where $K_{C}=\frac{3 n_{p} M}{2 L_{r}} \phi_{r}:$ Electromagnetic torque constant.

The correction gains of the Proportional-Integral controller are determining using pole placement method to fix the closed-loop system dynamics. The closed loop transfer function of the system represented by Figure 2 without load torque is:

$$
H_{\Omega}=\frac{\left(k_{p} . s+k_{i}\right) K_{C}}{J . s^{2}+\left(k_{p} K_{C}+f\right) s+k_{i} K_{C}}
$$

The transfer function $H_{\Omega}$ can be identified to a second-order system and controller gains can be calculated as follows:

$$
\begin{gathered}
k_{p}=\frac{2 \xi k_{i}}{\omega_{n}}-\frac{f}{K_{C}} \\
k_{i}=\frac{J \omega_{n}^{2}}{K_{C}}
\end{gathered}
$$

where $\xi$ is the damping ratio and $\omega_{n}$ the natural frequency. 
If the damping coefficient is equal to 1 , the speed response time $T_{r s}$ can be expressed in terms of the natural frequency. In this case, we can calculate the values of speed controller gains from the following relationship [16]:

$$
\omega_{n} T_{r s} \approx 4.8
$$

\section{Fuzzy logic control based on the PI gains adaptation}

In order to design a robust control law which takes in consideration the effect of the rotor resistance variation, without increasing the control scheme complexity and without using an observer, this section is devoted to the proposal of an adaptive PI controller structure with parameters adjustment using fuzzy logic. The fuzzy system generates the $k_{p}$ and $k_{i}$ parameters of the PI controller depending on the error signal as shown in Figure 3, to ensure high performance of the developed control law with compensation of the rotor resistance $\left(R_{r}\right)$ variation.

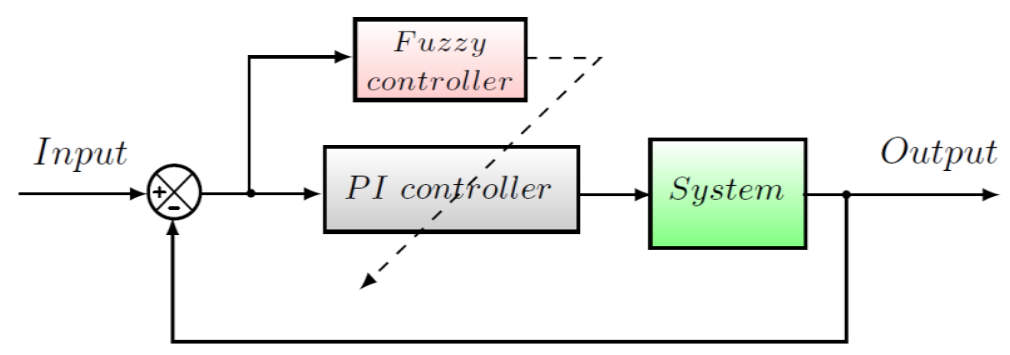

Figure 3. Block diagram of the fuzzy logic gains adaptation of the PI controller.

The proposed controller uses two fuzzy systems: the first generates the $k_{p}$ gain and the second generates $k_{i}$ via another auxiliary parameter $\alpha$. The proposed-PI fuzzy adaptation system is shown in Figure 4.

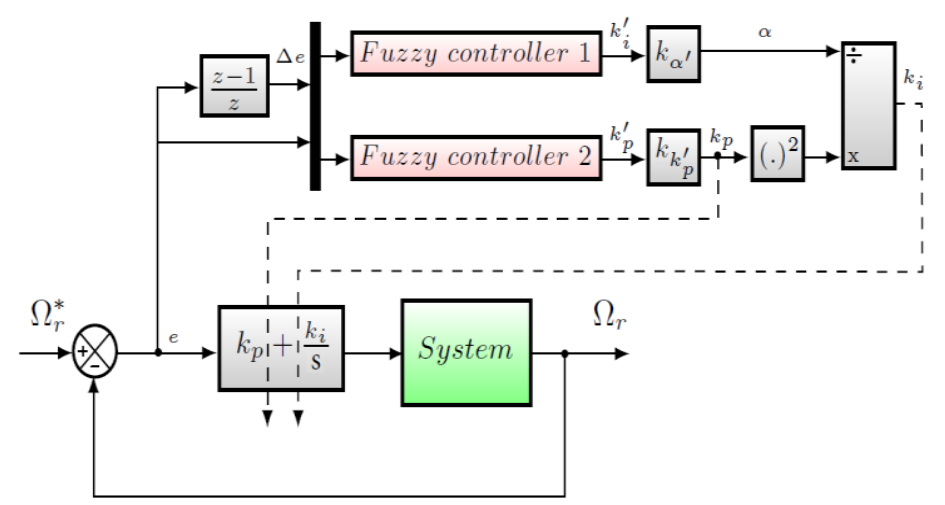

Figure 4. Block scheme of the proposed speed control loop.

As indicated in Figure 4, the PI parameters are determined from two fuzzy inferences whose outputs are auxiliary parameters, while inputs are the error between the real and referenced speed $(e)$, and its derivative $(\Delta e)$. The outputs of the two fuzzy controllers are standardized in intervals between zero and 1 . The parameters $k_{p}$ and $k_{i}$ are determined using the following equations:

$$
k_{p}=k_{k_{p}^{\prime}} \cdot k_{p}^{\prime}
$$




$$
k_{i}=\frac{k_{p}^{2}}{\alpha}
$$

To perform a mapping from an input vector to an output, the fuzzy inference engine must use the fuzzy IF THEN rules. The $\mathrm{i}^{\text {th }}$ fuzzy rules is written as follows:

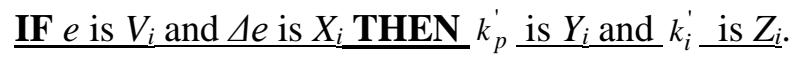

where $V_{i} ; X_{i} ; Y_{i}$ and $Z_{i}$ are the fuzzy sets.

The proposed triangular membership functions for both inputs $(e, \Delta e)$, as illustrated in Figure 5, are:

- $\quad N B$ (Negative Big);

- $N M$ (Negative Medium);

- $\quad N S$ (Negative Small);

- $P B$ (Positive Big);

- $P M$ (Positive Medium);

- $P S$ (Positive Small);

- $Z$ (Zero).

The defuzzification uses the center of gravity to compute the output of each fuzzy logic controller.

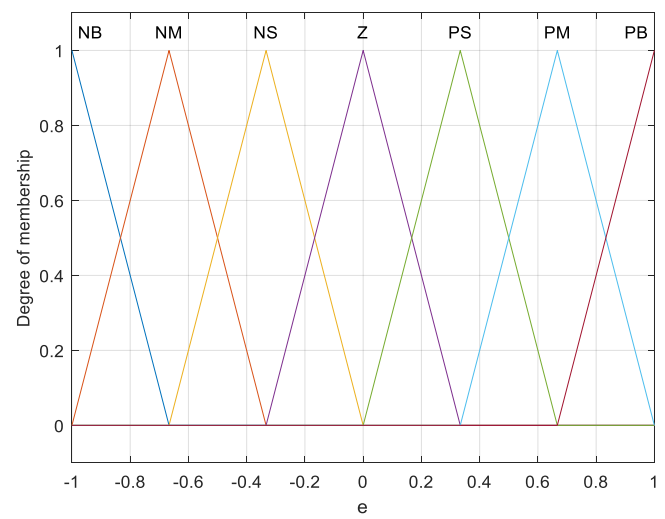

Figure 5. Membership functions for inputs.

For the output variable of the fuzzy logic controller that generates $k_{p}^{\prime}$, two membership functions are associated as shown in Figure 6. The membership functions for the output that generates $k_{i}^{\prime}$ are represented in Figure 7. 


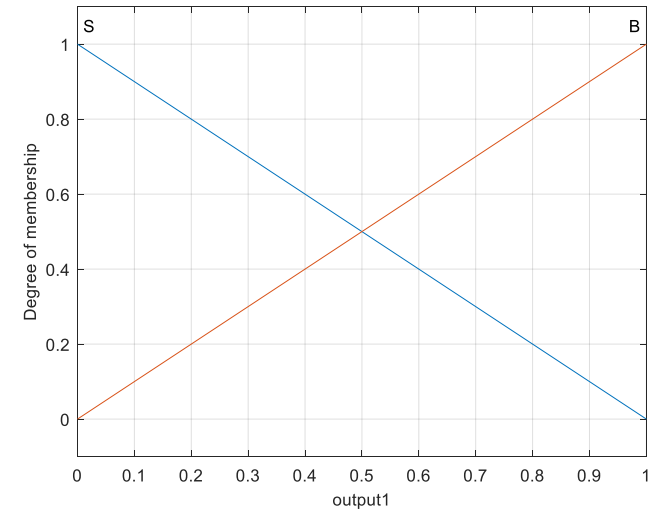

Figure 6. Membership functions for $k_{p}^{\prime}$.



Figure 7. Membership functions for $k_{i}^{\prime}$.

For our application, we used the basic rules given in Tables 1 and 2, which stem from expertise and are based on the operating principle of the bang-bang that offers very good results [2], with an idea to initially bring the system close to the desired operating point, and then change the polarity of the control variable to avoid overshoot. Indeed, for each pair of the input values, the mechanism causes a variation of the proportional and integral gains corresponding to the increase or decrease of the PI control law. So, to produce a large control signal, the PI controller must have a large proportional gain and a very small integral gain [29]. Tables 1 and 2 are organized as decision tables. The rules defining the output of each fuzzy controller which is carried out by using the Mamdani's method are represented in the following tables:

Table 1. Fuzzy control rules for $k_{p}^{\prime}$.

\begin{tabular}{|c|c|c|c|c|c|c|c|c|}
\hline \multicolumn{2}{|c|}{$k_{p}^{\prime}$} & \multicolumn{10}{|c|}{$\mathrm{e}$} \\
\cline { 2 - 9 } & & NB & NM & NS & Z & PS & PM & PB \\
\hline \multirow{4}{*}{$\Delta e$} & NB & PB & PB & PB & PM & PB & PB & PB \\
\cline { 2 - 8 } & NM & PB & PB & PM & PM & PM & PB & PB \\
\cline { 2 - 8 } & NS & PB & PM & PM & PS & PM & PM & PB \\
\cline { 2 - 8 } & Z & PB & PM & PM & PS & PM & PM & PB \\
\cline { 2 - 9 } & PS & PM & PM & PM & PS & PM & PM & PM \\
\hline
\end{tabular}




\begin{tabular}{|l|c|c|c|c|c|c|c|c|}
\hline & PM & PM & PM & PS & PS & PS & PM & PM \\
\cline { 2 - 7 } & PB & PM & PM & PS & Z & PS & PM & PM \\
\hline
\end{tabular}

Table 2. Fuzzy control rules for $k_{i}^{\prime}$.

\begin{tabular}{|c|c|c|c|c|c|c|c|c|}
\hline \multicolumn{2}{|c}{$k_{i}^{\prime}$} & \multicolumn{9}{|c|}{ e } \\
\cline { 2 - 9 } \multicolumn{1}{c|}{} & NB & NM & NS & Z & PS & PM & PG \\
\hline \multirow{4}{*}{$\Delta e$} & NB & PM & PS & Z & Z & Z & PS & PM \\
\cline { 2 - 8 } & NM & PM & PS & Z & Z & Z & PS & PM \\
\cline { 2 - 8 } & NS & PM & Z & Z & Z & Z & Z & PM \\
\cline { 2 - 8 } & Z & PS & Z & Z & Z & Z & Z & PS \\
\cline { 2 - 8 } & PS & PS & Z & Z & Z & Z & Z & PS \\
\cline { 2 - 8 } & PM & PS & Z & Z & Z & Z & Z & PS \\
\cline { 2 - 8 } & PB & PS & Z & Z & Z & Z & Z & PS \\
\hline
\end{tabular}

\section{Simulation results and discussion}

The effectiveness of the proposed PI field oriented control of induction motor with gains adaptation has been verified by simulations. The proposed adaptive proportional-integral fuzzy logic vector control scheme of electric motor drive is illustrated in Figure 8 . The simulation results have been obtained by implementing the developed control scheme under the Matlab-Simulink environment with $50 \mu$ s sampling period. The motor parameters are given in Table 3 .

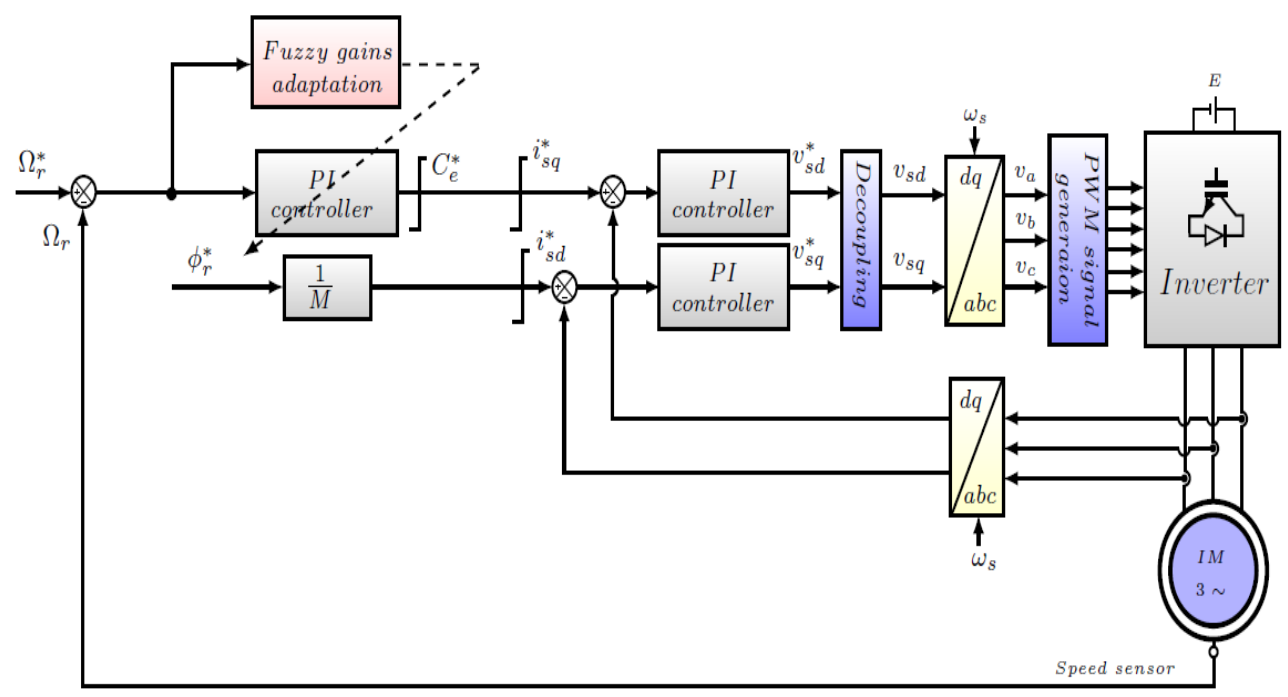

Figure 8. Block diagram of the vector control with an adaptive PI fuzzy logic gains adaptation.

Table 3. Induction motor parameters values.

\begin{tabular}{|l|c|c|}
\hline \multicolumn{1}{|c|}{ Designation } & Notations & $\begin{array}{c}\text { Rating } \\
\text { values }\end{array}$ \\
\hline Stator resistance & $R_{s}$ & $2.3 \Omega$ \\
\hline Rotor resistance & $R_{r}$ & $1.83 \Omega$ \\
\hline Stator self-inductance & $L s$ & $261 \mu \mathrm{H}$ \\
\hline Rotor self-inductance & $L_{r}$ & $261 \mu \mathrm{H}$ \\
\hline Mutual inductance & $M$ & $245 \mu \mathrm{H}$ \\
\hline Moment of inertia & $J$ & $0.03 \mathrm{kgm}^{2}$ \\
\hline Friction coefficient & $f$ & $0.002 \mathrm{Nm}$ \\
\hline Number of poles & $n_{p}$ & 2 \\
\hline
\end{tabular}




\begin{tabular}{|l|l|l|}
\hline Rated power & $P_{n}$ & $3 \mathrm{~kW}$ \\
\hline Rated voltage & $V_{s n}$ & $220 \mathrm{~V}$ \\
\hline
\end{tabular}

\subsection{Step speed operation with load torque application and rotor resistance variation}

Three tests were performed. The first one was for the classical PI speed control. A step reference speed was applied at $\mathrm{t}=1 \mathrm{~s}$ and is equal to $157 \mathrm{rad} / \mathrm{s}$. The load torque is applied at $\mathrm{t}=3 \mathrm{~s}$, and it is equal to $10 \mathrm{Nm}$. At $\mathrm{t}=5 \mathrm{~s}$, a disturbance was undergone on the rotor resistance which has been increased by $50 \%$ from its rated value. The second test was for the adaptive control, where the classical PI controller was replaced by the proposed adaptive PI fuzzy logic controller, used the same speed profile and the same operating conditions. The final test was for an adaptive control, using the MRAS observer.

Figure 9,10 and 11 show the simulation results for the classical PI without gains adaptation. Figure 9 shows that the rotor speed has decreased by almost $10 \mathrm{rad} / \mathrm{s}$ from its rated value, and the rotor speed error illustrated by Figure 10 shows that this error has exceeded $7 \%$ when the rotor resistance undergone a variation, due to the flux orientation being lost, as shown in Figure 11.

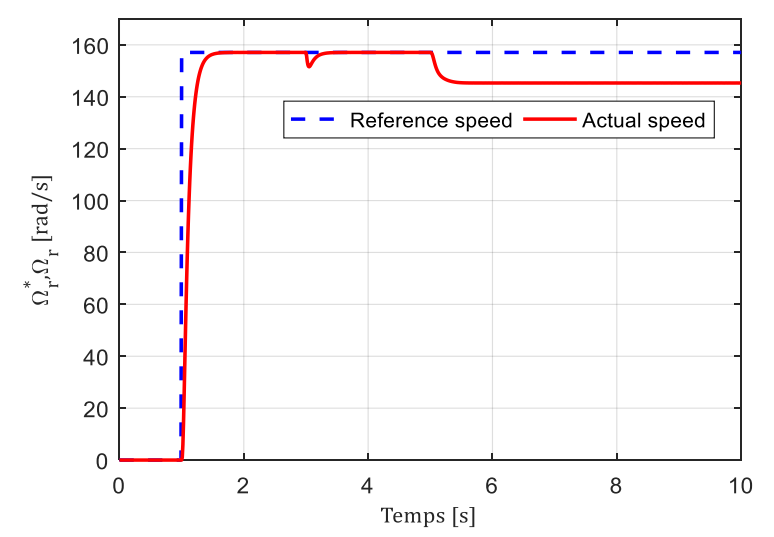

Figure 9. Rotor speed (without PI gains adaptation).

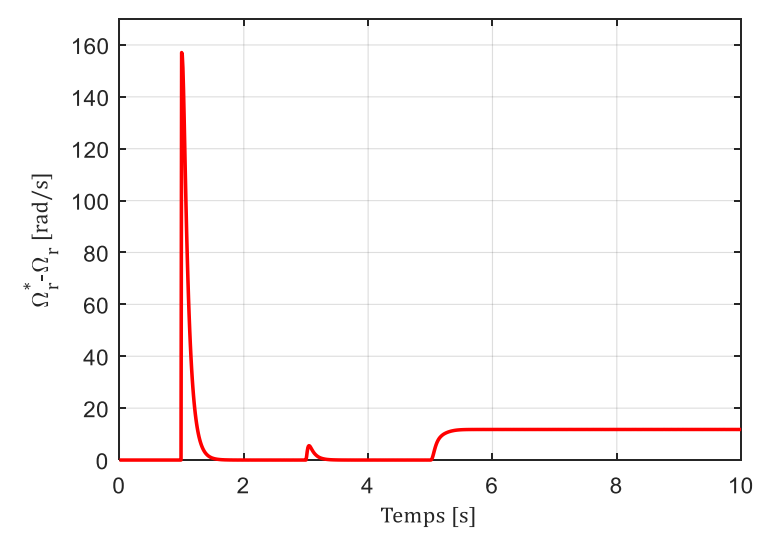

Figure 10. Rotor speed error (without PI gains adaptation). 


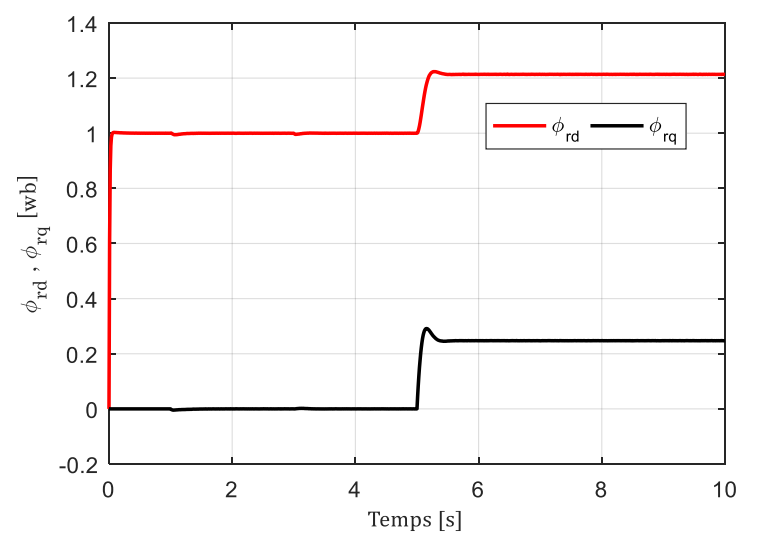

Figure 11. Rotor flux (without PI gains adaptation).

Figure 12, 13 and 14 show the performance of the proposed adaptive control with fuzzy logic gains adaptation of the PI speed controller. The obtained results show that if the rotor resistance undergoes anincreaseat $\mathrm{t}=5 \mathrm{~s}$, the proposed adaptive control still gives a good orientation of the rotor flux and a good speed tracking, with a speed error which does not exceed $1 \%$ of the rated value.

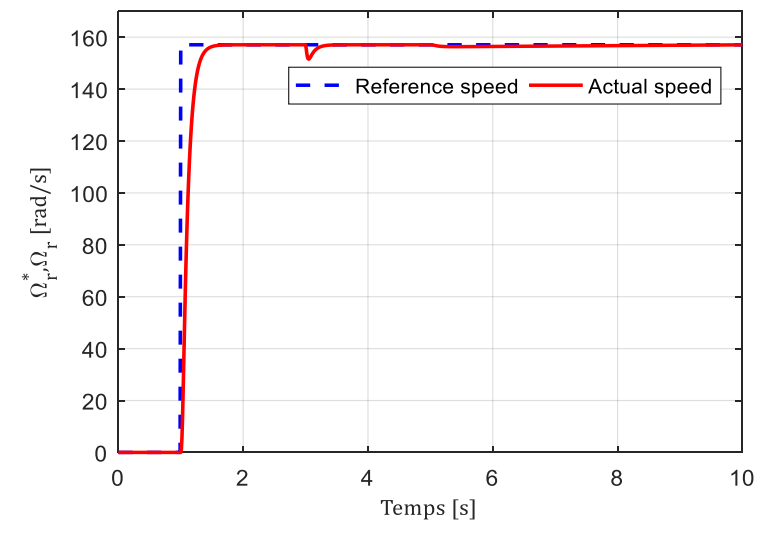

Figure 12. Rotor speed (with PI gains adaptation).

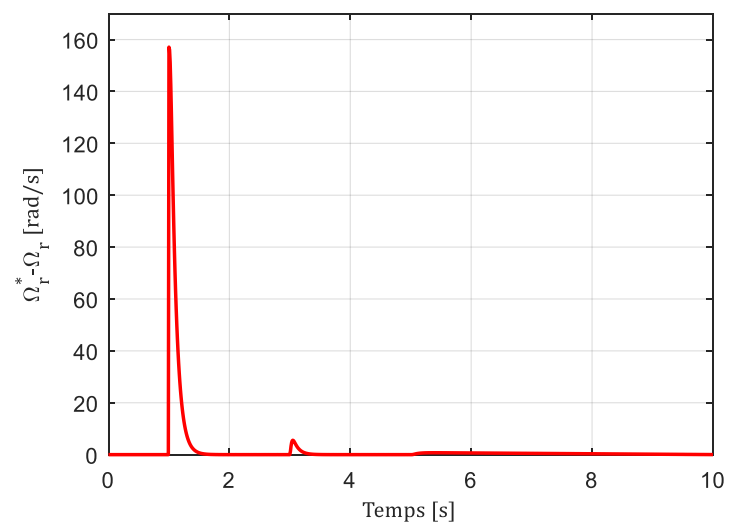

Figure 13. Rotor speed error (with PI gains adaptation). 




Figure 14. Rotor flux (with PI gains adaptation).

However, the adaptive control using the MRAS observer does not guarantee a good tracking of the rotor speed as shown in Figure 12. In this case, when the rotor resistance undergoes a variation, the rotor speed decreases by almost $2 \mathrm{rad} / \mathrm{s}$ from its rated value with the appearance of ripples, as shown in Figure 15 and 16.

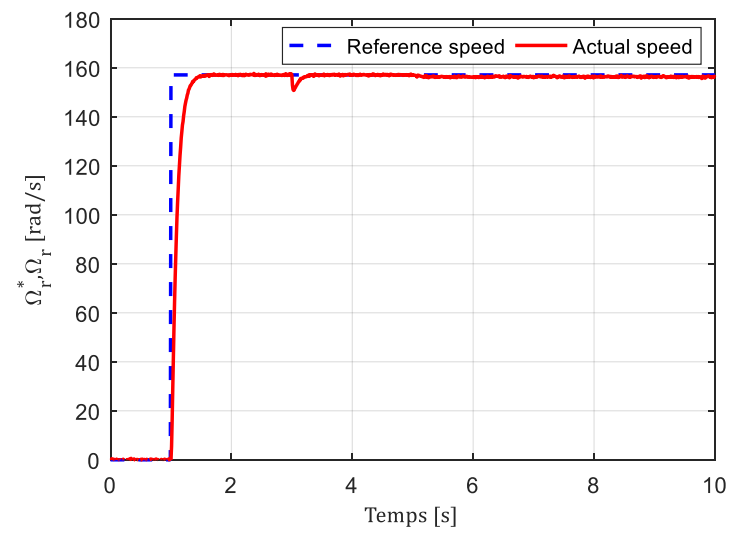

Figure 15. Rotor speed (with the MRAS $R_{r}$ observer).

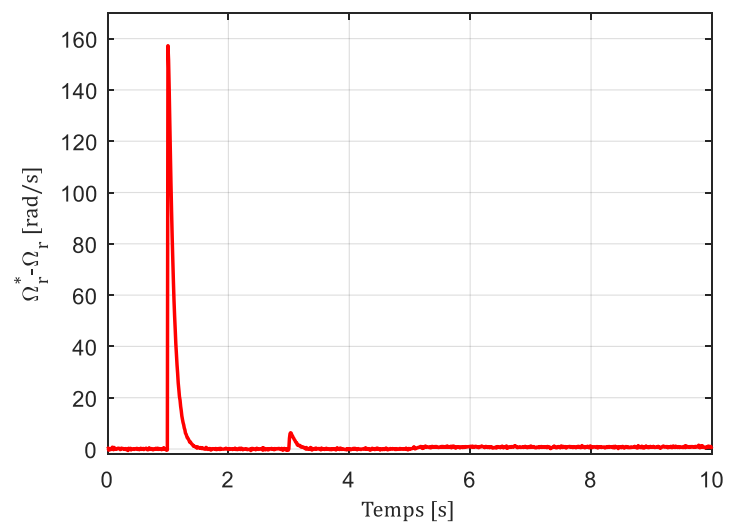

Figure 16. Rotor speed error (with the MRAS $R_{r}$ observer). 


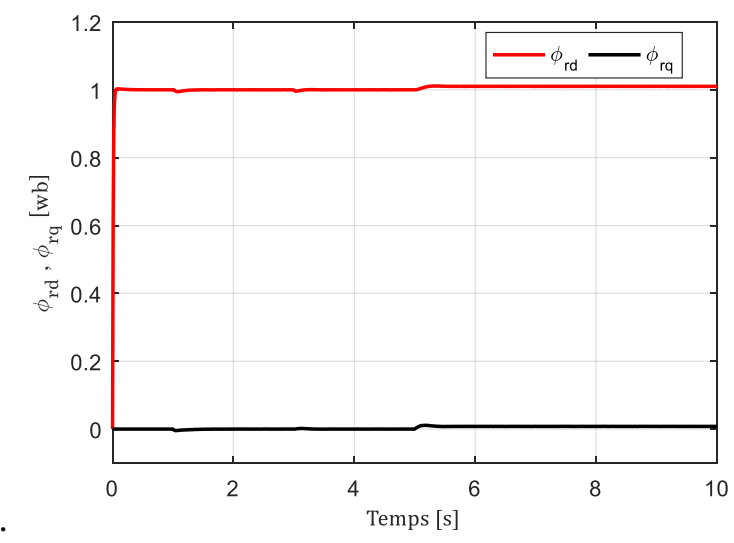

Figure 17. Rotor flux (with the MRAS $R_{r}$ observer).

Figure 17 shows that using the MRAS rotor resistance observer makes an error appear according to the $\mathrm{d}$ and q flux axes which does not guarantee a good fluxes orientation.

Table 4 shows the performance indices comparison between the proposed adaptive control scheme, the classical PI control and the adaptive control using the MRAS rotor resistance observer. The quality of control criteria are given as follows:

$$
\begin{aligned}
I A E & =\int_{0}^{\infty}|E(t)| d t \\
I T A E & =\int_{0}^{\infty} t .|E(t)| d t \\
I S E & =\int_{0}^{\infty} E^{2}(t) d t
\end{aligned}
$$

The equations (11), (12) and (13) show that the IAE performance indices penalize the positive and negative values of the error by calculating the area generated by the difference between the set-point and the actual value. The ITAE performance indices penalizes long-lasting transient dynamics of error, however the $I S E$ performance index will penalize big errors more than smaller ones.

The obtained results illustrate the superiority of the adaptive proportional-integral fuzzy logic control compared to the classical PI control and the MRAS method.

Table 4. Performance indices:

$\Omega_{r}^{*}, \phi_{r}^{*}:$ References values, $\Omega_{r}, \phi_{r d}:$ Actual values .

\begin{tabular}{|c|c|c|c|c|}
\hline $\begin{array}{c}\text { Control } \\
\text { Method }\end{array}$ & $E$ & IAE & ITAE & ISE \\
\hline \multirow{2}{*}{$\begin{array}{c}\text { Classical } \\
\text { PI control }\end{array}$} & $\Omega_{r}^{*}-\Omega_{r}$ & 148 & 8629 & 3684 \\
\cline { 2 - 5 } & $\phi_{r d}^{*}-\phi_{r d}$ & 1.068 & 8.025 & 0.2293 \\
\hline Adaptive & $\Omega_{r}^{*}-\Omega_{r}$ & 25.5 & 90.35 & 1403 \\
\hline
\end{tabular}




\begin{tabular}{|c|c|c|c|c|}
\hline MRAS & & & & \\
\cline { 2 - 5 } control & $\phi_{r d}^{*}-\phi_{r d}$ & 0.11 & 0.65 & 0.001 \\
\hline $\begin{array}{c}\text { Proposed } \\
\text { adaptive PI } \\
\text { control }\end{array}$ & $\Omega_{r}^{*}-\Omega_{r}$ & 16.08 & 18.38 & 373 \\
\cline { 2 - 5 } $\begin{array}{c}\text { with gains } \\
\text { adaptation } \\
\text { based on } \\
\text { fuzzy logic }\end{array}$ & $\phi_{r d}^{*}-\phi_{r d}$ & 0.004 & 0.01 & $1.95 \mathrm{e}^{-05}$ \\
\hline
\end{tabular}

\subsection{Robustness Tests}

The performance of the proposed control scheme which is based on an adaptive proportional-integral fuzzy logic controller are assessed again with other three tests using the same conditions mentioned in the previous subsection 4.1, which are performed to study the influence of the parametric variations for the stator and rotor inductances, and inertia coefficient of the induction motor.

The simulation results of robustness tests illustrated by Figure 18, 19 and 20 show clearly that the parametric variations of the induction motor has practically no effect on the dynamics of speed response, even in the presence of the rotor resistance variation.

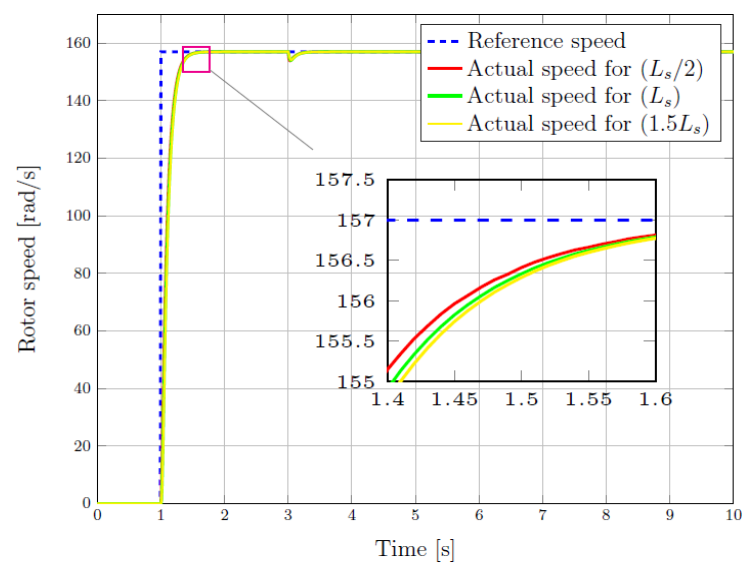

Figure 18. Rotor speed in case of the stator inductance variation (with PI gains adaptation).

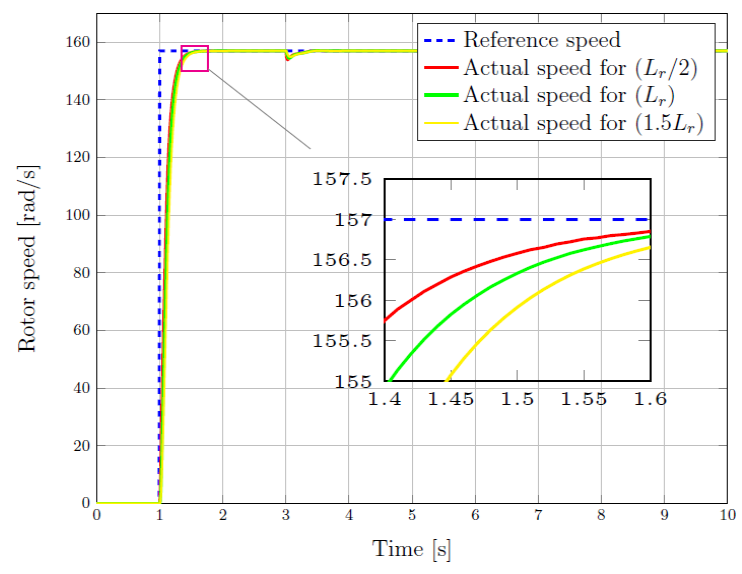

Figure 19. Rotor speed in case of the rotor inductance variation (with PI gains adaptation). 


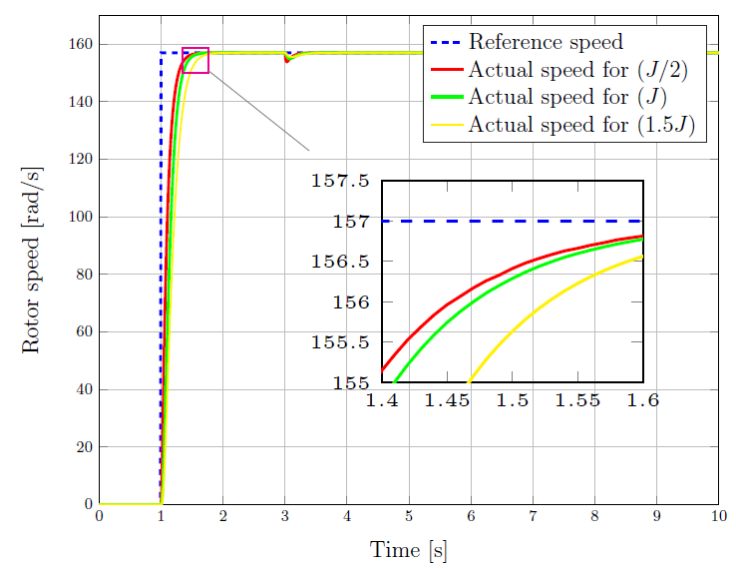

Figure 20. Rotor speed in case of the moment of inertia variation (with PI gains adaptation).

The obtained results show clearly that the proposed adaptive proportional-integral fuzzy logic control has a powerful approach to allow high performance control. Consequently, from the simulation results, we note that the PI control with gains adaptation based on fuzzy logic can guarantee a better control performance of induction motor, and prove the efficacy of the proposed control scheme in terms of speed reference tracking in transients and stand-still operation, load disturbances rejection and rotor flux orientation, even in the presence of parametric variations.

\section{Conclusion}

The PI control with gains adaptation based on the fuzzy logic technique is developed in this paper. The proposed method is an alternative to handle the induction motor rotor resistance variation problem. These techniques use an adaptive mechanism of the PI speed controller gains which is ensured using a fuzzy logic controller for each gain $\left(k_{p}\right.$ and $\left.k_{i}\right)$.

The developed PI control with gains adaptation based on fuzzy logic can guarantee a high performance compared to the classical PI control and the adaptive control using the MRAS rotor resistance observer. The simulation tests confirm the theoretical concepts and show that this type of adaptive control can overcome the rotor resistance variation. The simulation results revealed that the proposed control scheme can guarantee a good performance because the speed error does not exceed $1 \%$ of the rated value.

\section{References}

[1] P. Parida, "A sliding mode controller for induction motor drives," Ph.D. Thesis, National Institute of Technology, 2009.

[2] K. Hasse, "On the dynamics of speed control of a static AC drive with squirrel cage induction machine," Ph. D. Thesis, Dissertation, Tech. Hochschule Darmstradt, 1969.

[3] F. Blaschke, "The principle of field orientation as applied to the new TRANSVECTOR closed loop control system for rotating field machines," in Siemens Rev, vol. 34, pp. 217-220, 1972.

[4] N. El Ouanjli, et al, "Modern improvement techniques of direct torque control for induction motor drives - a review," Protection and Control of Modern Power Systems, vol. 7, pp. 1-12, 2019.

[5] N. El Ouanjli, et al, "Improved DTC strategy of doubly fed induction motor using fuzzy logic controller," Energy Reports, vol. 5, pp. 271-279, 2019.

[6] F. Alonge, et al., "Input output feedback linearizing control of linear induction motor taking into consideration the end-effects, Part II: Simulation and experimental results," Control Engineering Practice, vol. 36, pp. 142-150, 2015.

[7] H. A. Shah and A. T. Patel, "Controller design via sliding mode control approach of induction motor a survey," in 4th International Conference on Advanced Computing Communication Technologies (ACCT), India, pp. 541-546, 2014.

[8] O. Barambones and P. Alkorta, "A robust vector control for induction motor drives with an adaptive 
sliding-mode control law," Journal of the Franklin Institute, vol. 348, pp. 300-314, 2011.

[9] C. Ben Regaya, et al., "Loss minimizing with backstepping technique control for induction motors and on line adaptation of the stator and rotor resistance," Middle East Journal of Scientific Research, vol. 15, pp. 389-397, 2013.

[10] C. Ben Regaya, et al., "Adaptive discrete-time backstepping control of irrigation station," Advanced Systems and Electric Technologies (IC_ASET), pp. 158-163, 2017.

[11] C. Ben Regaya, et al., "An adaptive sliding-mode speed observer for induction motor under backstepping control," Innovative Computing, Information and Control (ICIC Express Letters), vol. 11, pp. 763-771, 2017.

[12] F.Farhani, et al., "Real time PI-backstepping induction machine drive with efficiency optimization," ISA Transactions, vol. 70, pp. 348-356, 2017.

[13] W. Chakchouk, et al., "Discrete-time adaptive backstepping control: Application to pumping station," Proceedings of the Institution of Mechanical Engineers, Part I: Journal of Systems and Control Engineering, vol. 232, pp. 683-694, 2018.

[14] C. Ben Regaya, et al., "High-performance control of IM using MRAS-fuzzy logic observer," International Conference on Advanced Systems and Electric Technologies (IC_ASET), pp. 158-163, 2017.

[15] C. Ben Regaya, et al., "A novel adaptive control method for induction motor based on backstepping approach using dspace ds 1104 control board," Mechanical Systems and Signal Processing, vol. 100, pp. 466-481, 2018.

[16] M. Gayathri, et al., "Comparison of rotor flux and reactive power based mras rotor resistance estimators for vector controlled induction motor drive," International Conference on Advances in Engineering, Science and Management (ICAESM), India, pp. 183-189, 2012.

[17] C. Ben Regaya, et al., "A new sliding mode speed observer of electric motor drive based on fuzzylogic," Acta Polytechnica Hungarica, vol. 11, pp. 219-232, 2014.

[18] A. Zaafouri, et al., "DSP-based adaptive backstepping using the tracking errors for high-performance sensorless speed control of induction motor drive," ISA Transactions, vol. 60, pp. 333-347, 2016.

[19] C. Ben Regaya, et al., "Comparison between two methods for adjusting the rotor resistance," International Review on Modelling and Simulations, vol. 5, pp. 938-944, 2012.

[20] K. Negadi, et al., "Hardware implementation of vector control of induction motor drive without speed encoder using an adaptive luenberger based MRAS observer," Mechanical Systems and Signal Processing, vol. 20, pp. 99-114, 2012.

[21] V. Azimi, et al., "Fuzzy Mixed-Sensitivity Control of Uncertain Nonlinear Induction Motor," Majlesi Journal of Electrical Engineering, vol. 8, pp. 45-53, 2014.

[22] A. Savoia, et al, "Adaptive flux observer for induction machines with on-line estimation of stator and rotor resistances," in Proceedings of the 15th International Power Electronics and Motion Control Conference (EPE/PEMC '12), pp. 1-6, 2012.

[23] W. Chakchouk, et al., "Fuzzy supervisor approach design based-switching controller for pumping station: experimental validation," Mathematical Problems in Engineering, pp. 1-12, 2017.

[24] H. Hamdi, et al., "Real-time study of a photovoltaic system with boost converter using the PSO-RBF neural network algorithms in a MyRio controller," Solar Energy, vol. 183, pp. 1-16, 2019.

[25] N. El Ouanjli, et al, "High Performance Direct Torque Control of Doubly Fed Induction Motor using Fuzzy Logic," Journal of Science, vol. 31, pp. 532-242, 2018.

[26] S. Preitl and R. E. Precup, "Iterative feedback tuning in fuzzy control systems. Theory and applications," Acta Polytechnica Hungarica, vol 3, pp. 81-96, 2006.

[27] S. Vrkalovic, et al., "Stable takagi-sugeno fuzzy control designed by optimization," International Journal of Artificial Intelligence, vol. 15, pp. 17-29, 2017.

[28] C. Ben Regaya, et al., "Electric drive control with rotor resistance and rotor speed observers based on fuzzy logic," Mathematical Problems in Engineering, pp. 1-9, 2014.

[29] K. Sang-Hoon, "Electric Motor Control: Control of direct current motors," ELSEVIER Book, pp. 39-93, 2017. 